\title{
EDITORIAL
}

\section{EL CAMINO HACIA LA EXCELENCIA \\ CIENTÍFICA: LOS INDICADORES \\ BIBLIOMÉTRICOS Y LA EFECTIVIDAD \\ DE LAS INVESTIGACIONES JURÍDICAS}

\author{
THE PATH TO SCIENTIFIC EXCELLENCE: \\ BIBLIOMETRIC INDICATORS AND THE \\ EFFECTIVENESS OF LEGAL RESEARCH \\ O CAMINHO PARA A EXCELÊNCIA CIENTÍFICA: \\ OS INDICADORES BIBLIOMÉTRICOS E A \\ EFETIVIDADE DAS PESQUISAS JURÍDICAS
}

DOI: $10.5294 / D I K A .2017 .26 .1 .1$

Este volumen de Díkaion es el primero editado por quien suscribe, Luciano D. Laise, quien se ha incorporado como profesor de tiempo completo a la Facultad de Derecho y Ciencias Politicas de la Universidad de La Sabana. Sin embargo, corresponde agradecer de todo corazón al anterior editor, el profesor José Julián Suárez Rodríguez, por su colaboración en este número y por la tenaz gestión editorial que realizó en los últimos años.

Díkaion es una de las pocas revistas científicas del mundo de habla hispana cuya linea editorial se dirige a cuestiones de fundamentación jurídica. Esto implica, en efecto, que no solo publica trabajos de teoría o filosofia del derecho, sino también artículos que parten de una perspectiva dogmática, pero que exploran cuestiones relativas a los principios sobre los que se erigen disciplinas jurídicas tales como el derecho constitucional, penal, tributario, administrativo, civil, laboral, por caso. En otras palabras, Díkaion da la bienvenida a todos los trabajos que someten a discusión los puntos de partida de las diferentes áreas del conocimiento jurídico.

No obstante, si bien el núcleo esencial de la política editorial de Díkaion continúa siendo el mismo, quisiera poner de relieve que 
hemos comenzado el largo recorrido hacia indexaciones de la revista en bases de datos prestigiosas tales como Scopus o Web of Science. La decisión de emprender este camino implicó modificar parcialmente algunos procesos operativos y varias de las estrategias que guian el desarrollo de esta revista. Todos estos cambios se resumen en dos cuestiones fundamentales: 1) un mayor grado de internacionalización - tanto en lo relativo a los artículos que se aceptan como en la integración del comité editorial y en la designación de los evaluadores-; 2) una mayor relevancia de las métricas en la gestión y la politica editorial de esta publicación periódica.

La relevancia de la internacionalización de una revista científica, en particular una que se concentra en cuestiones de fundamentación jurídica, no merece mayores explicaciones. Es casi un lugar común que la investigación científica se enriquece con una pluralidad de voces que provienen de diferentes y variados ambientes universitarios. En el caso de las indagaciones relativas a la fundamentación jurídica es claro que existen amplias posibilidades de incrementar la calidad de los resultados de investigación mediante un silencioso diálogo internacional entre investigadores provenientes de diversas latitudes. Solo es preciso remarcar que Díkaion procurará el desarrollo de la contribución de autores y evaluadores de diversas nacionalidades, sin desmerecer el criterio fundamental de la calidad y el rigor científico.

En relación con las métricas es preciso aclarar que de ningún modo pretendemos dar lugar a "citas ornamentales"; esto es, referencias que en nada contribuyen a comprender mejor lo que se estudia en un trabajo científico. Todo lo contrario, lo que pretendemos alcanzar son "citas efectivas"; esto es, que Díkaion sea frecuentemente referida en otras publicaciones periódicas por la excelencia de su nivel científico y por el impacto de sus contribuciones al desarrollo de la ciencia jurídica. En consecuencia, las métricas de la revista habrán de incrementarse en la misma medida en que aumente su nivel científico. Es por ello que este camino de indexación requiere necesariamente de publicaciones de excelencia como aquellas que integran este número.

Así, el primer trabajo, escrito por el doctor José Antonio Santos, profesor de la Universidad Rey Juan Carlos, de España, se titula "El hombre tecnológico como fetiche de la modernidad ampliada. Un diálogo con la posmodernidad como resistencia de Jesús Ballesteros”. En este artículo se defiende la tesis de que, dentro del contexto de la modernidad ampliada, todo es incierto y relativo. Esto opera como un fecundo punto de partida para analizar cómo el capitalismo y el individualismo radicales han propiciado una imagen decadente del "hombre tecnológico", una situación que muestra el triunfo del materialismo y la decadencia de los valores culturales, éticos y jurídicos en relación con la comprensión del transhumanismo. Este panorama sirve para establecer un diálogo con la posmodernidad como resistencia que propone Jesús Ballesteros; es decir, como un medio capaz de oponerse a la injusticia y la inhumanidad del mundo actual. Por último, el autor brinda un modesto esbozo de una ética jurídica del débil que sirva como alternativa a la actual imagen tecnológica del hombre. Una concepción que persigue dejar una mejor humanidad para las generaciones futuras, tanto desde el punto de vista ético como jurídico. 
El segundo trabajo fue redactado por el doctor Raúl Madrid Ramírez, profesor de la Universidad Católica de Chile, y lleva por título: "La noción de bienestar subjetivo y el concepto de derecho. A propósito del vínculo entre normas jurídicas y felicidad humana”. El mencionado autor se ocupa de analizar la idea contemporánea del bienestar subjetivo — subjective well being - como equivalente actual de la clásica noción de felicidad, así como los parámetros que de este bienestar subjetivo se derivan para formular una relación con el derecho, entendido como el conjunto de prescripciones normativas vigentes en la comunidad. Con este propósito, el artículo describe sintéticamente la noción tradicional aristotélica de felicidad, para comparar las diferencias entre esta y la idea de bienestar subjetivo, cuyo desarrollo exhaustivo ocupa el cuerpo del trabajo. Las conclusiones que arroja esta investigación dan cuenta de una conexión metodológica entre el concepto de subjective well being y la comprensión del derecho.

El tercer artículo se titula "La dimensión objetiva de los derechos fundamentales en México”. Este trabajo examina la dimensión objetiva de los derechos fundamentales en ese país. La centralidad de esta perspectiva conlleva tres consecuencias principales: el efecto irradiación de los derechos, los mandatos de acción al Estado y la eficacia horizontal de los derechos. El aspecto que parece más problemático es justamente este último, no tanto desde su elaboración teórica sino, sobre todo, por sus implicancias adjetivas. Porque, en efecto, el juicio de amparo parece seguir siendo improcedente contra las violaciones de los derechos fundamentales que procedan de terceros.

El cuarto artículo fue escrito por el doctor Enoc Francisco Morán Torres, profesor de la Universidad de Colima, México, y lleva por titulo: "Transfuguismo: dicotomía entre la lealtad partidaria y la participación politica: una visión desde los precedentes judiciales en México". El transfuguismo que ha caracterizado el sistema político mexicano se ha convertido, en los últimos años, en una cuestión de relevancia constitucional a partir de ciertos matices que han sido desarrollados por la máxima autoridad jurisdiccional en materia electoral de México: el Tribunal Electoral del Poder Judicial de la Federación, e incluso la Suprema Corte de Justicia de la Nación. En sintesis, la investigación trata sobre el análisis de la figura del transfuguismo, de forma preponderante desde la fase de la candidatura, a partir de algunos precedentes que han emitido órganos jurisdiccionales mexicanos, en el contexto del sistema presidencial que caracteriza a ese país.

El quinto y último trabajo fue redactado por la académica Norma Elizabeth Levrand, de la Universidad Nacional del Litoral, Argentina, y se titula: "Como pieza de un rompecabezas: la construcción del paisaje como objeto jurídico”. El artículo toma como punto de partida que la regulación jurídica del paisaje es relativamente novedosa. Esto se debe a que el paisaje suele ser concebido a partir de la interrelación entre el hombre y la naturaleza. Es por ello que el derecho lo ha asimilado, en ciertos momentos históricos, a un objeto estático. Posteriormente, se ha captado el esencial dinamismo del paisaje y se lo ha regulado como un objeto híbrido porque, en efecto, el paisaje está constituido por un conjunto de bienes y valores que trascienden lo puramente cultural o natural, pero en el que ambos 
extremos se articulan; esto es, la cultura y la naturaleza. Este carácter híbrido conlleva dificultades que han sido examinadas en esta investigación, tanto en lo relativo al diseño de su regulación normativa como al momento de su aplicación e implementación concreta.

Finalmente, quisiera culminar este escrito con un cálido agradecimiento a cada uno de los autores por las contribuciones que son publicadas en este número. Y, por supuesto, la rigurosidad de los evaluadores es otro de los pilares fundamentales en que se apoya el nivel científico de Díkaion. A todos ellos, y al equipo editorial de esta revista, les agradecemos por su sincera colaboración.

LUCIANO D. LAISE

Editor Revista Díkaion

Luciano.laise@unisabana.edu.co 